\title{
Experimental Study and Engineering Practice of Pressured Water Coupling Blasting
}

\author{
J. X. Yang and C. Y. Liu \\ Key Laboratory of Deep Coal Resource Mining, Ministry of Education of China, China University of Mining \& Technology, \\ Xuzhou 221116, China \\ Correspondence should be addressed to J. X. Yang; jxyangcumt@163.com
}

Received 24 March 2017; Revised 27 August 2017; Accepted 29 August 2017; Published 3 October 2017

Academic Editor: Sundararajan Natarajan

Copyright ( 92017 J. X. Yang and C. Y. Liu. This is an open access article distributed under the Creative Commons Attribution License, which permits unrestricted use, distribution, and reproduction in any medium, provided the original work is properly cited.

\begin{abstract}
Overburden strata movement in large space stope is the major reason that induces the appearance of strong mining pressure. Presplitting blasting for hard coal rocks is crucial for the prevention and control of strong pressure in stope. In this study, pressured water coupling blasting technique was proposed. The process and effect of blasting were analyzed by orthogonal test and field practice. Results showed that the presence of pressure-bearing water and explosive cartridges in the drill are the main influence factors of the blasting effect of cement test block. The high load-transmitting performance of pore water and energy accumulation in explosive cartridges were analyzed. Noxious substances produced during the blasting process were properly controlled because of the moistening, cooling, and diluting effect of pore water. Not only the goal of safe and static rock fragmentation by high-explosive detonation but also a combination of superdynamic blast loading and static loading effect of the pressured water was achieved. Then the practice of blasting control of hard coal rocks in Datong coal mine was analyzed to determine reasonable parameters of pressured water coupling blasting. A good presplitting blasting control effect was achieved for the hard coal rocks.
\end{abstract}

\section{Introduction}

Presplitting blasting control of hard coal rocks, permeability and splitting enhancing measures for low-permeability coal seams, pressure relief and transfer of deep high stress, and prevention and control of dynamic load are important issues in safety mining of modernized mines [1]. China's shallow coal resources are about to be depleted, and the exploitation of deep coal sources represents the latest trend. The mining of deep thick and ultrathick coal seams can easily lead to extensive overburden strata movement and to the formation of distinct large space stope. Stress distribution in the stope is very complex with the appearance of strong mining pressure. When the overburden strata are enriched with multiple layers of hard roof, the large breaking step distance of hard roof may cause high-intensity weighting for the stope. As a result, the support crushing accidents on the working face may occur, with severe subsidence of roadway roof, floor heave, and rib spalling $[2,3]$. Therefore, in the excavation of modernized deep mines, effective presplitting blasting of hard coal rocks is important for the prevention and control of strong mining pressure. Along with the rapid economic development, rock blasting technology has found extensive applications in water conservancy, hydropower, mines, and transport and has generated huge social and economic benefits [4-6]. However, its application to complex environment of coal mines has been restricted $[1,7]$. Existing studies have shown that the wave impedance matching between explosives in the blast hole and the surrounding rock of hole wall is conducive to the utilization of the explosion energy and thus to a good rock-breaking effect [8-11]. Hydraulic blasting is based on the incompressibility and inertial effect of aqueous media, and the blasting effect is much better than detonation in drill hole [12-15]. However, hydraulic blasting involves complex blasting procedures and limitations are imposed on borehole sealing technology and equipment. For these reasons, the application of hydraulic blasting to coal mine production is not fully understood $[13,16]$. It is very urgent to improve the 
blasting technique in coal mine production, so as to achieve a low-cost, high-performance presplitting blasting effect of coal rocks.

The pressured water coupling blasting which is based on traditional blasting techniques uses pressured fluids or coupled solid-fluid media in place of the air in the borehole for the purpose of improving the wave impedance of the detonation transmission medium. It can help to reduce the blast energy loss, cut the explosive charge per unit volume of rock, and improve the targeting efficiency of the shock waves in the borehole. The wedging action of the pressured water can boost rock fracturing, thus enlarging the fracture zone around the borehole [17-19]. The technique can improve the working environment and ensure safe mining operations, and it is especially applicable to highly gassy mines [1,12].

Given the complex coal mining environment, the physical and mechanical features of coal rocks usually differ greatly. Traditional hydraulic blasting can hardly maintain continuous load transmission due to the infiltration and filtration loss of the fractured coal rocks. Here, we proposed the modified technique of pressured water coupling blasting, where the confined water is injected into the drill hole for detonation with pressure. This method can give full play to the load transmission performance of pore-fissure water. However, it remains unclear whether pressure bearing of pore-fissure water is the major influence factor of presplitting blasting effect of coal rocks under specific mining conditions of coal rocks and whether there are other significant influence factors as well. There usually exists a great variety of factors that influence borehole blasting of coal mines. In this study, experimental analysis was performed to determine the main influence factors of pressured water coupling blasting of hard coal rocks $[20,21]$. The research results provide reference for the field optimization of presplitting blasting of hard coal rocks.

\section{Occurrence and Strata Behaviors}

The excavation of the Jurassic coal seam in Datong coal mine is approaching an end. Now the focus has been shifted to the mining of deep ultrathick carboniferous coal seams. The spacing between carboniferous and Jurassic coal seams is about $150-200 \mathrm{~m}$. Sandy lithology is dominant in the interseam strata, accounting for about $90 \%-95 \%$. The advancing directions of the working face are perpendicular to each other. The average length of the working face in the overburden Jurassic coal seam is $150 \mathrm{~m}$. The coal pillar width in the goaf is $40 \mathrm{~m}$. The roof breaks and forms an arc shape, with a caved height of $121 \mathrm{~m}$. The residual coal pillars impose the majority of weight as the overburden at the arch foot. The plane layout of the Jurassic and carboniferous coal seams and the overburden profile are shown in Figure 1.

The arch structure of roof in the stope of the Jurassic coal seam is usually associated with stress concentration in the floor under the coal pillar [22]. Calculation has indicated that the stress concentration in the floor under the coal pillar exerts an influence to the depth of about $100 \mathrm{~m}$. Compared with the mining condition with a 150-200 $\mathrm{m}$ spacing between the coal seams, the residual coal pillars in the goaf of the Jurassic coal seam are not sufficient, which affects the mining of ultrathick carboniferous coal seam underlying it. When the overburden disturbance caused by the mining of the underlying ultrathick coal seam has affected the region of stress concentration in the overlying coal pillars, the elastic energy accumulated in this region will be released. The reactivation of the roof of the Jurassic coal seam will produce a large impact on the mining of the underlying ultrathick carboniferous coal seams [2, 3, 22], as shown in Figure 2.

The following measures are usually used to improve the mining environment in deep coal mine: reducing mining pressure, adopting effective presplitting blasting measures for hard coal rocks, blocking load transmission in hard coal rocks, and providing buffer against the strong dynamic load induced by motion instability of the main roof of thick hard overburden. Based on these measures, the pressure of pore-fissure water is preset to improve the load transmission performance during explosion. The purpose is to fully drive out the air from the pores and fissures and to improve the utilization of energy generated by the explosion. For thick hard roof, the explosives are arranged to different segments of the borehole. The shock front produced by explosion will act on the surrounding rock of the hole wall several times, which ensures the full presplitting of the hard coal rocks. After borehole explosion, water medium that propagates the explosion will expand and enhance the splitting. As the pores and fissures become interconnected, the scope of overall weakening of roof increases. Moreover, explosion in a water environment generates less dust and the noxious substances released by explosion are also properly controlled. Here we first performed an experimental study on pressured water coupling blasting control and analyzed the blasting process and effect. The main controlling factors of pressured water coupling blasting control were identified.

\section{Experiment Analysis}

Underwater blasting often shows both a high efficiency of explosive energy transfer and a high rate of destruction of underwater structures $[1,12-15]$. Given the low strength of the home-made cement blocks, two levels of explosive charges, $3 \mathrm{~g}$ and $8 \mathrm{~g}$, were used in the test to avoid the potential danger of flying rock fragments. The initial water pressure was set at $0 \mathrm{MPa}$ and $3 \mathrm{MPa}$, which allowed the assessment of blasting effectiveness in different confinement conditions and facilitated sealing the borehole. Then the levels of the experimental factors were calculated from these quantities, as shown in Table 1.

Each cement block sample had dimensions of $50 \times 50 \times$ $50 \mathrm{~cm}$ and weighed $250 \mathrm{~kg}$, with a density of $2,000 \mathrm{~kg} / \mathrm{m}^{3}$ and an average uniaxial compressive strength of $28.76 \mathrm{MPa}$. The preparation of one block sample required $32 \mathrm{~L}$ of water, $167 \mathrm{~kg}$ of cement, and $83 \mathrm{~kg}$ of sand.

To facilitate the loading of explosive and the selection of suitable steel tube, the borehole diameter in the samples was fixed at $40 \mathrm{~mm}$ and the burial depth of the water inlet pipes was fixed at $150 \mathrm{~mm}$. Each pipe had an internal diameter of $42 \mathrm{~mm}$ and an external diameter of $45 \mathrm{~mm}$. The steel pestle measuring $40 \mathrm{~mm}$ in diameter was used to make the holes in the cement block samples. 


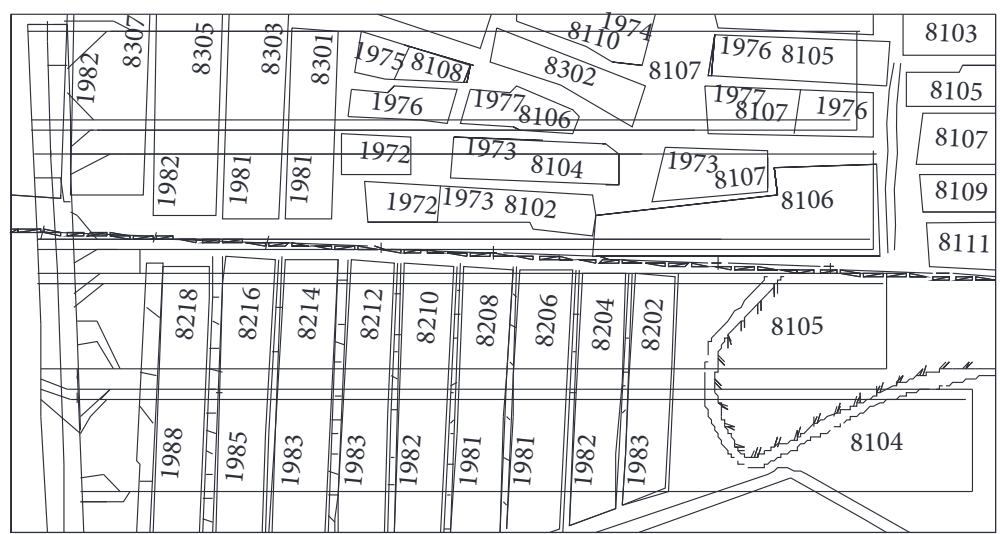

(a) Plane layout of coal seams

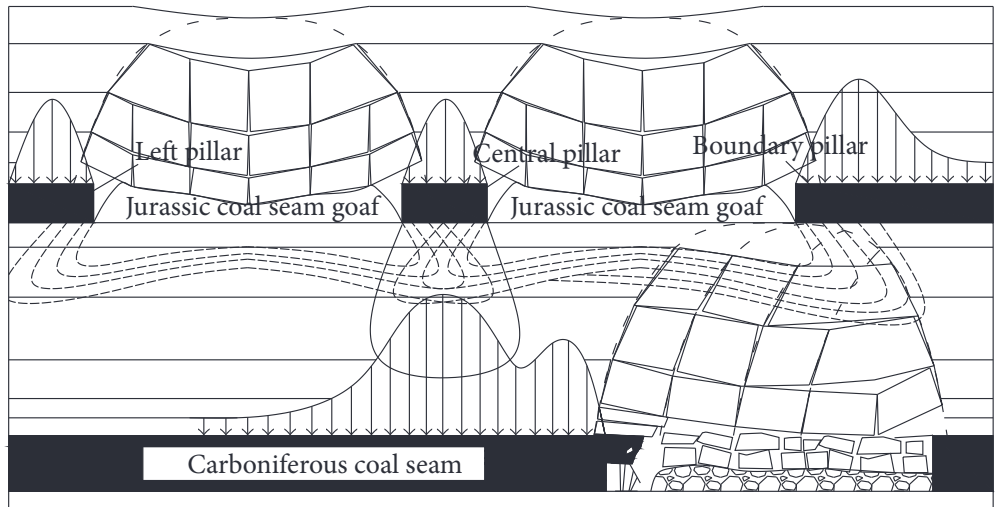

(b) Overburden profile

FIGURE 1: Plane layout of Jurassic and carboniferous coal seams and overburden profile.

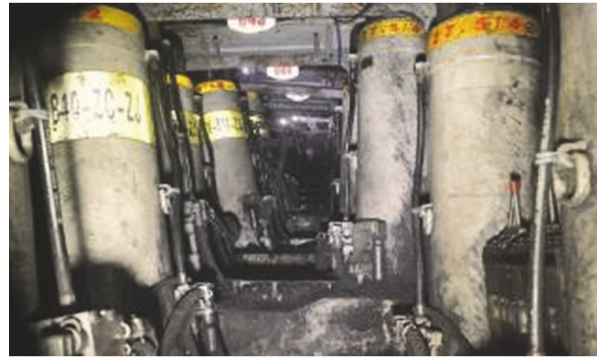

(a) Columns crushing

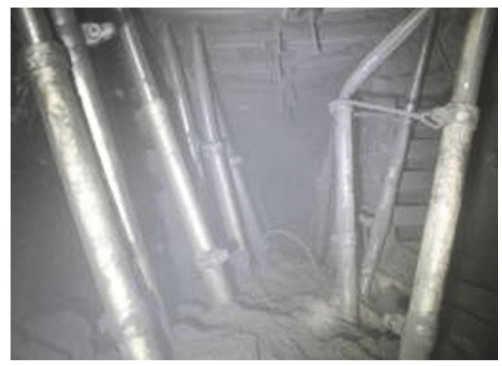

(b) Props damage

FIGURE 2: Appearance of strong mining pressure in the ultrathick coal seams.

TABLE 1: Experimental factors and levels.

\begin{tabular}{lcc}
\hline Experimental factor & \multicolumn{2}{c}{ Factor levels } \\
\hline Explosive charges/g & $8(\mathrm{~A} 1)$ & $3(\mathrm{~A} 2)$ \\
Water pressure/MPa & $0(\mathrm{~B} 1)$ & $3(\mathrm{~B} 2)$ \\
Cartridge & With $(\mathrm{C} 1)$ & Without $(\mathrm{C} 2)$ \\
\hline
\end{tabular}

The blasting test was carried out outdoors in a quarry for safety. Considering the complex operating environment, a crane was needed to deliver the home-made large samples of cement blocks. The tools, moulds, equipment, and related monitoring devices used in the test are shown in Figure 3.

Due to the relatively higher density and lower compressibility of water relative to air, pressured water coupling blasting in borehole differs from ordinary blasting in the presence of air in some ways, despite their similarities. Then, a multifactor pressured water coupling blasting test was conducted on some home-made cement blocks to observe and analyze the process and results. Figure 4 illustrates how to connect the tubes and wires, load explosive, and seal the borehole. 


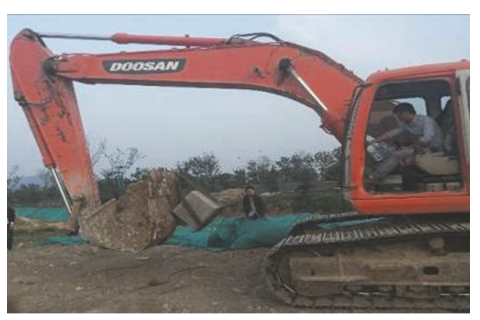

(a)

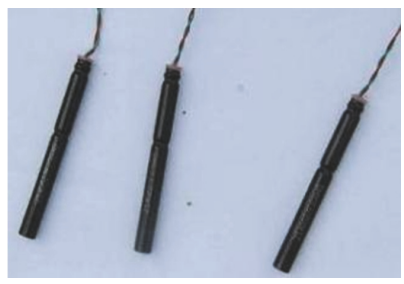

(e)

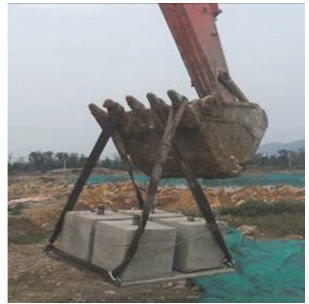

(b)

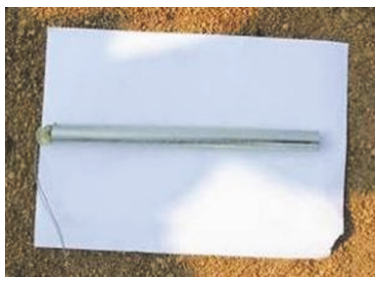

(f)

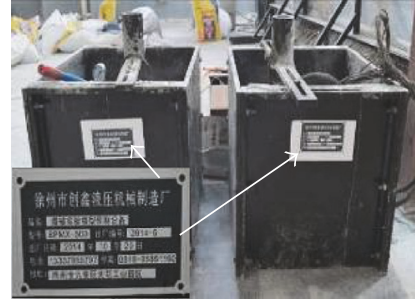

(c)

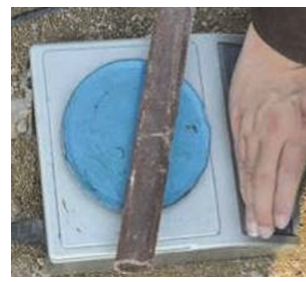

(g)

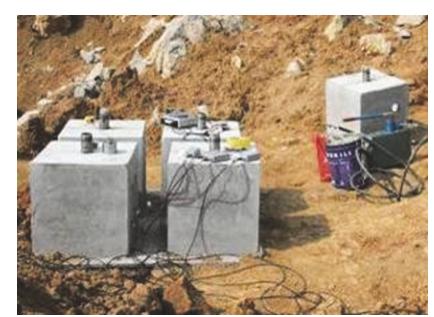

(d)

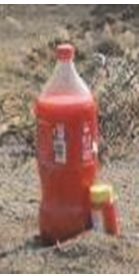

(h)

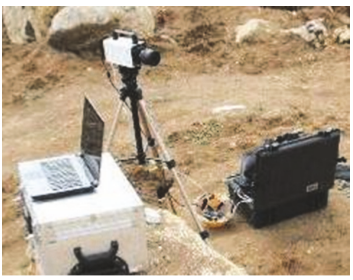

(i)

Figure 3: Pressured water coupling blasting test equipment: (a) delivery of a single block; (b) delivery of a few blocks; (c) the mould for making cement blocks; (d) prepared block samples; (e) detonator; (f) home-made cartridge; (g) ammonium nitrate explosive and electronic scale; (h) colored water; (i) high-speed camera.

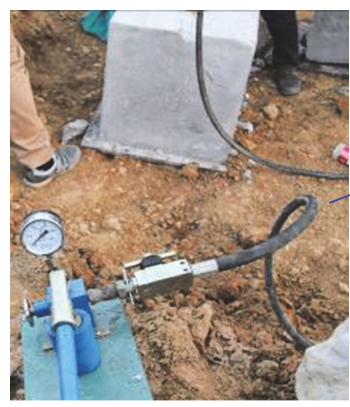

(a)

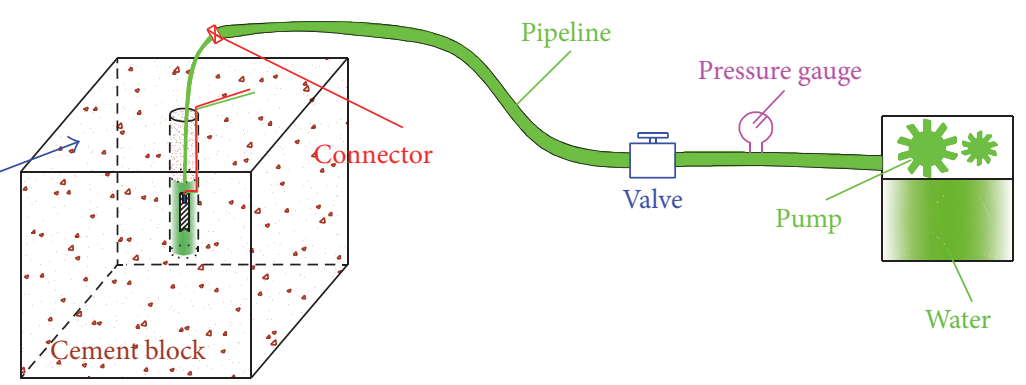

(b)

FIGURE 4: Operations in (a) connecting tubes and wires and (b) loading explosive and sealing borehole.

3.1. The Effectiveness of Ordinary Blasting. Before the pressured water coupling blasting test, an ordinary blasting test was carried out using $10 \mathrm{~g}$ of explosive [23]. The results of the test would provide guidance on the choice of proper explosive charges and be compared against the results of the later test. The states of the cement block before and after being blasted in ordinary conditions are shown in Figure 5.

The process of rock breakage by ordinary blasting in the presence of air was recorded by the high-speed camera (Figure 6).

As shown in Figure 6, a high temperature gas flow with bright flames burst out of the borehole immediately after the explosion. Later, the explosion products in the borehole expanded quickly and pressed the borehole wall. Then cracks initiated at the centers of the block's free faces and a large volume of white dust was released from the borehole mouth and the fracture surfaces. At the end, the rock around the borehole was completely split into fragments of varying sizes under the influence of the expanding explosion products in the borehole. These rock fragments gained kinetic energy and flew outward, accompanied by the production of gases and dust in large quantities.

\subsection{The Effectiveness of Pressured Water Coupling Blasting.} Figure 6 displays the states of the cement block before and after being blasted in the $\mathrm{A} 1 \mathrm{~B} 1 \mathrm{Cl}$ case.

As shown in Figure 7, the large cement block was ultimately broken into small rock fragments of relatively uniform sizes (with their characteristic sizes ranging from $0.07 \mathrm{~m}$ to $0.26 \mathrm{~m}$ ) despite a reduction in the explosive charge.

The high-speed camera recorded the process of cement block fragmentation by blasting in the A1B1Cl case (Figure 8).

Figure 8 shows that the high temperature products released by the explosion in this case were largely controlled at once. Though a small fraction of the products burst out of the borehole, they carried no flame or dust due to the diluting effect of water vapor. Later, the periphery of the block began to fracture evenly under the influences of both the explosion products and the water. The explosion products and the water spouted out of the borehole after breaking 


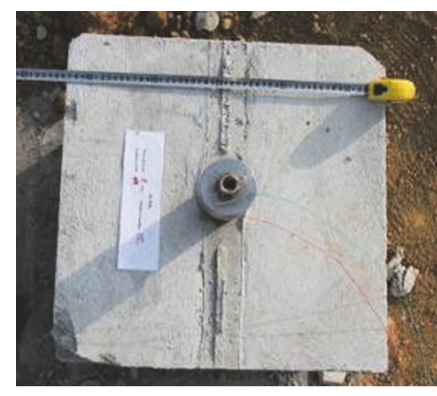

(a)

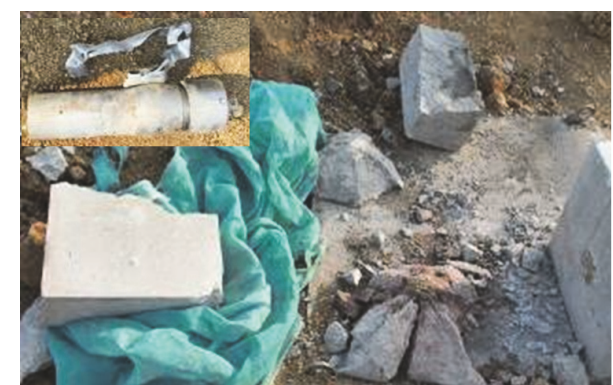

(b)

FIGURE 5: The states of the cement block: (a) before and (b) after being blasted.

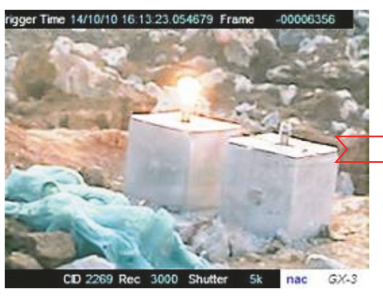

(a)

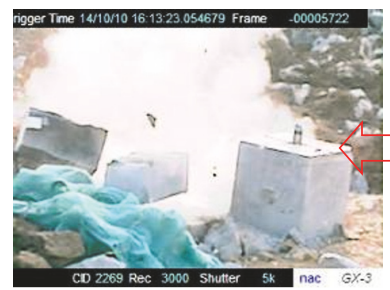

(h)

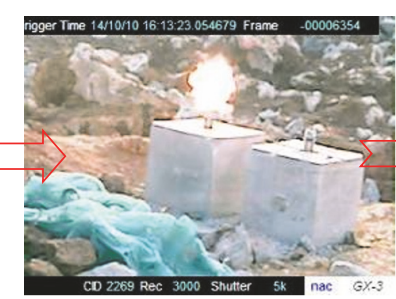

(b)

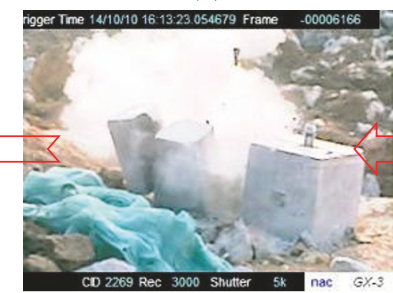

(g)

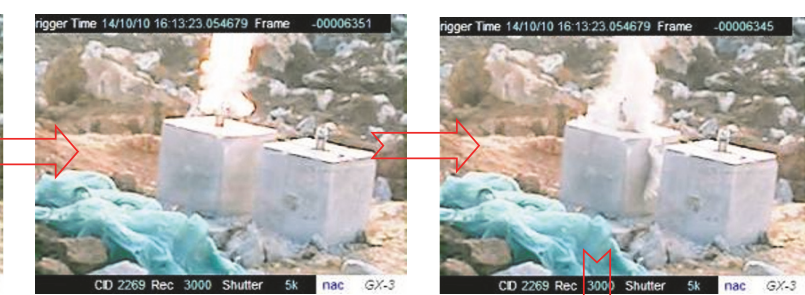

(c)

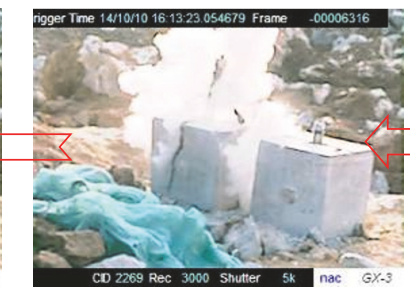

(f) (d)

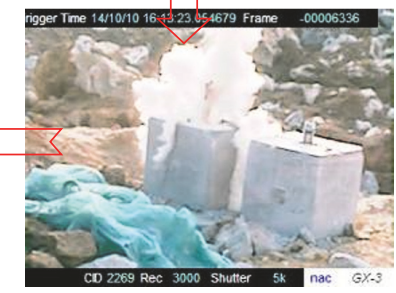

(e)

Figure 6: The process of ordinary blasting in the presence of air: (a) No. 6356; (b) No. 6354; (c) No. 6351; (d) No. 6345; (e) No. 6336; (f) No. 6316; (g) No. 6166; and (h) No. 5722 frame.

though the blind nut, rather than being immediately forced out along the cracks as observed in the ordinary blasting test. This difference demonstrated that the water expands more slowly than the air under high pressure conditions. As the large scale fracturing began to occur, the pressure of the mixture of explosion products and water dropped to a certain level, and thus the broken rock could absorb a small amount of kinetic energy from the mixture. As a result, only a few rock fragments were thrown for short distances $(<4.3 \mathrm{~m})$.

Figure 9 displays the states of the cement block before and after being blasted in the A2B1C2 case.

It is observed that a small amount of explosive had relatively low brisance, but the explosion had a relatively uniform effect on the cement block, due to the existence of the water. In this case, a large block was evenly split into four pieces by only $3 \mathrm{~g}$ of explosive. Figure 10 displays the process of cement block fragmentation in the A2B1C2 case.

The macroscopic blast effect at the moment of explosion in this experiment was similar to that observed using $8 \mathrm{~g}$ of explosive in the $\mathrm{A} 1 \mathrm{~B} 1 \mathrm{C} 1$ case. In both cases, small quantities of explosion products burst out of the borehole and the heat, flame, and dust were effectively diluted by the water vapor. But the results of the two experiments differed significantly in terms of the resulting rock fragments. In this case, the rock fragments were larger and uniform in size. Overall, the blasting process using a small charge of explosive without cartridge was comparatively stable and showed no violent dynamic response, which is common in blasting processes. Therefore, it can be concluded that the water around the explosive in the borehole has good load transfer capability and the strong dynamic load resulting from the explosion will act on the surrounding rock in a manner similar to static rock fragmentation.

In the $\mathrm{A} 2 \mathrm{~B} 2 \mathrm{C} 1$ case, a small amount of explosive confined by pressurized water was exploded in the presence of a cartridge. The states of the cement block before and after being blasted are shown in Figure 11.

The cement block was also evenly split into four fragments, similar to the results of the A2B1C2 case. The process of rock fragmentation is shown in Figure 12.

Unlike in the A2B1C2 case, the blast energy was highly concentrated in this experiment. Driven by the highly concentrated energy in the borehole, the explosion products and the water burst out of the borehole in a radial pattern. When the explosive was not encased in a cartridge, these materials spurt from the borehole mainly in columnar shape. 


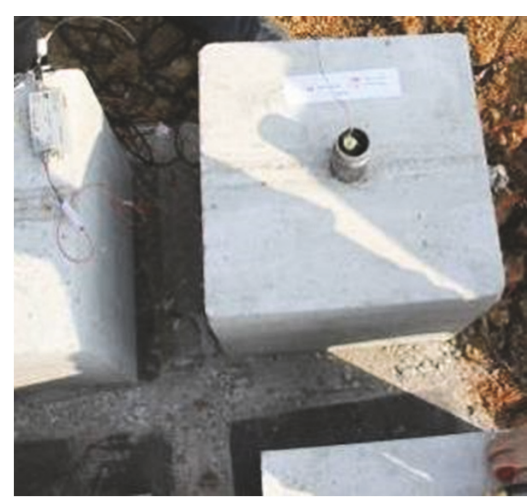

(a)

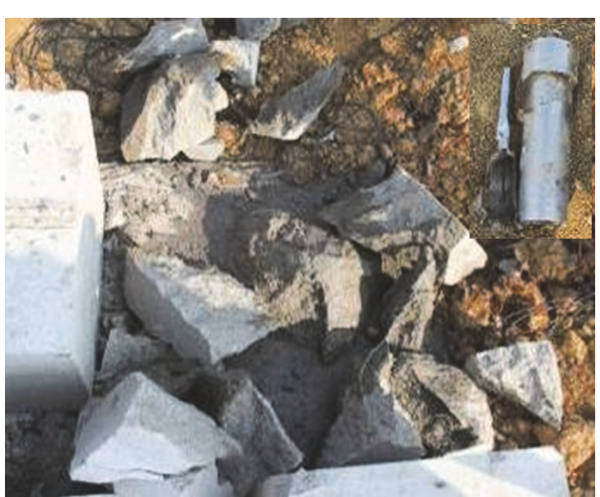

(b)

Figure 7: The states of the cement block in the A1B1C1 case: (a) before and (b) after being blasted.

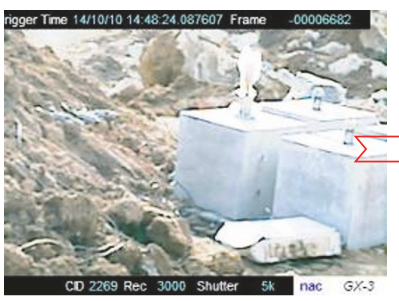

(a)

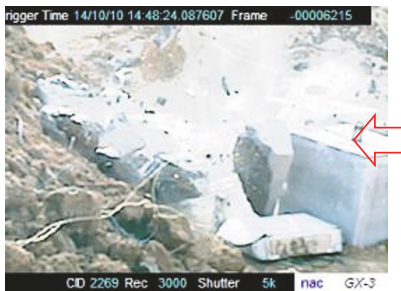

(h)

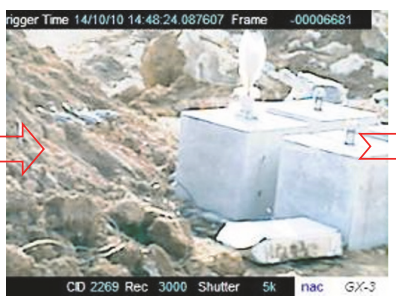

(b)

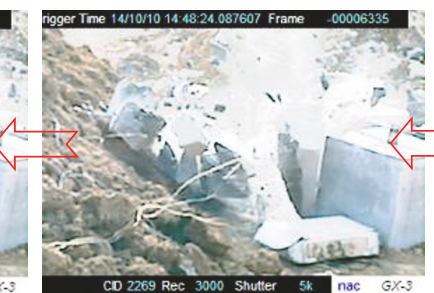

(g)

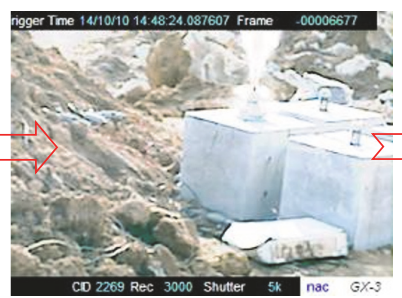

(c)

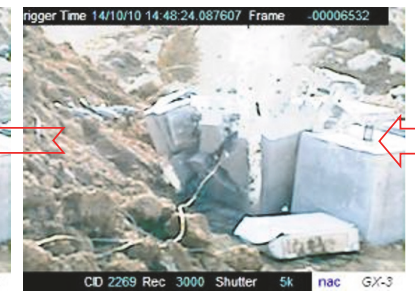

(f)

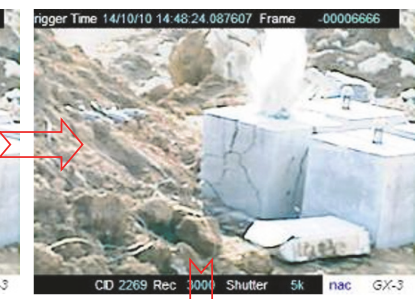

(d)

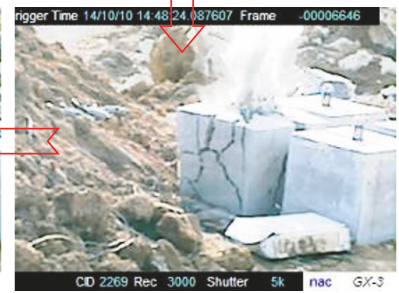

(e)

Figure 8: The process of pressured water coupling blasting in the A1B1C1 case: (a) No. 6682; (b) No. 6681; (c) No. 6677; (d) No. 6666; (e) No. 6646; (f) No. 6532; (g) No. 6335; and (h) No. 6215 frame.

Figure 13 illustrates the states of the cement block before and after being blasted in the A1B2C 2 case.

It is noteworthy that as the operator spent too much time in adjusting the hand pump, the detonator failed to detonate the explosive which had long been immersed in the pressurized water in this experiment. This can be proved by the black powder in Figure 13(c). Thus the breakage of this cement block was entirely caused by the explosion of detonator. This demonstrated that the pressured water with excellent energy transfer capability enabled the energy of a minimum explosive charge to break the rock effectively.

In this experiment, the high-speed camera did not capture any dynamic details of the process because the rock fragmentation caused by the explosion of detonator generated no distinct dynamic response.

3.3. Optimization of the Pressured Water Coupling Blasting. It is difficult to quantify the results of pressured water coupling blasting test performed on cement blocks because of the complex blast conditions, the production of sound, light, gases, and dust, and the extreme rapidity of high-explosive detonation. In this context, some nonquantitative indices, such as the intensity of sound, intensity of flames, dust output, and the degree and mode of rock fracturing, can be used in the classification and quantitative evaluation of test results.

The specific scoring method and score levels should be determined according to actual situations. The classification should be as detailed as possible in order to draw more accurate conclusions. In this study, the intensity of sound, intensity of flames, dust output, characteristic sizes of rock fragments, and duration of dust particles in the air were selected as the indices for evaluating the results. The specific scoring criteria are as follows.

The intensity of the sound produced by rock blasting was divided into five levels. The higher the sound intensity, the lower the score the test case would get. For example, an extremely strident sound corresponded to a score of 1 , whereas a weak sound produced by a nearly static blasting process corresponded to a score of 5 . 


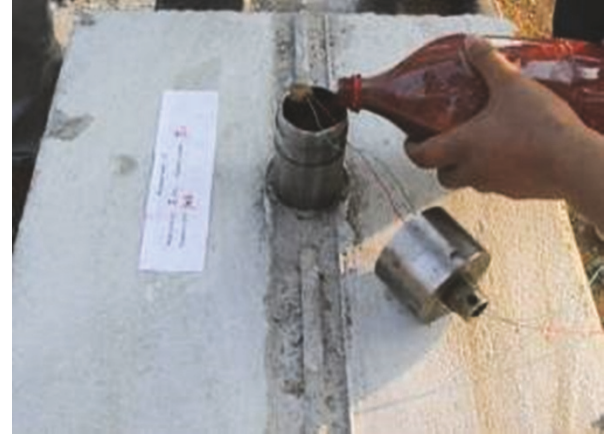

(a)

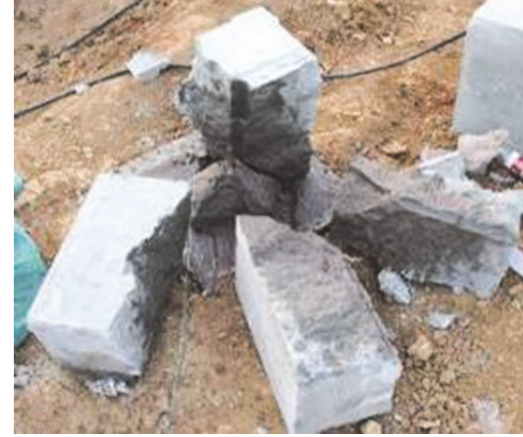

(b)

FIGURE 9: The states of the cement block in the A2B1C2 case: (a) before and (b) after being blasted.

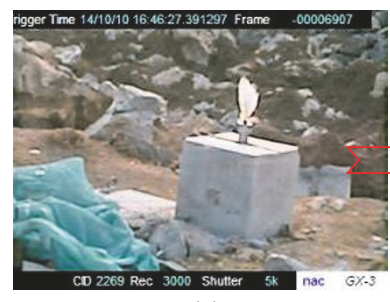

(a)

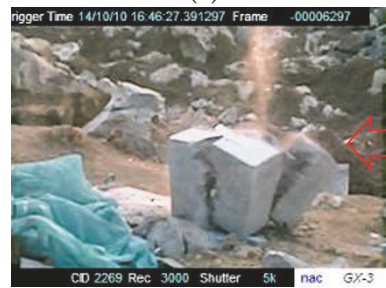

(h)

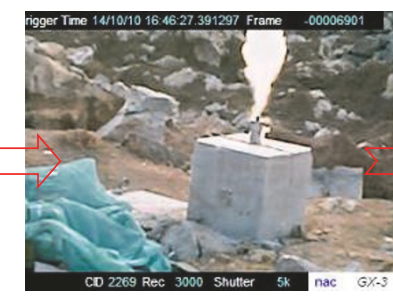

(b)

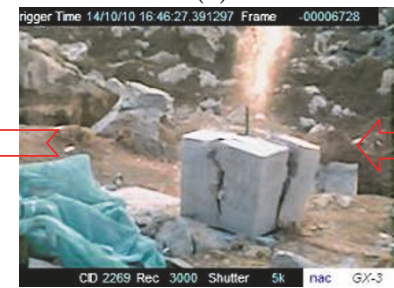

(g)

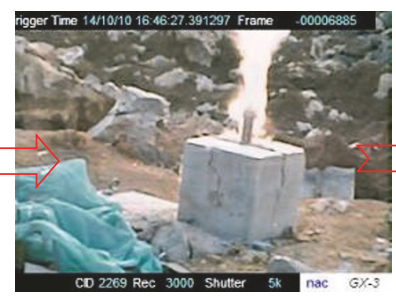

(c)

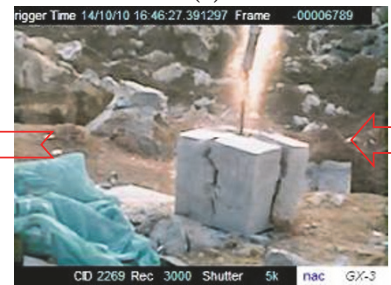

(f)

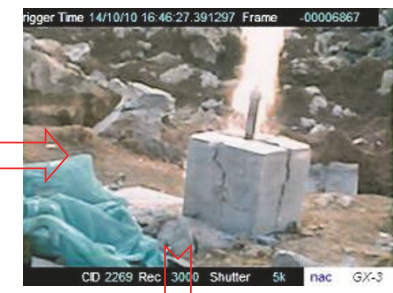

(d)

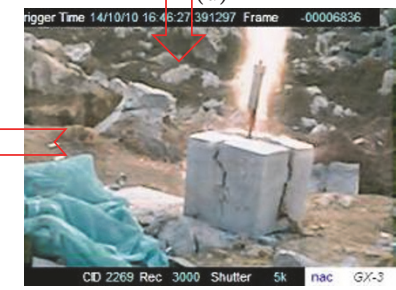

(e)

Figure 10: The process of pressured water coupling blasting in the A2B1C2 case: (a) No. 6907; (b) No. 6901; (c) No. 6885; (d) No. 6867; (e) No. 6836; (f) No. 6789; (g) No. 6728; and (h) No. 6297 frame.

In terms of the intensity of the flames produced, the experiments showing noticeable flames would get a score of 1 , while those exhibiting no flame would score 2 .

The dust output from the blasting process was categorized into 5 levels. The heavy smoke corresponded to a score of 1 , while a small volume or the absence of dust corresponded to a score of 5 .

The characteristic sizes of rock fragments were divided into three levels. If the resultant rock fragments were large $(>0.25 \mathrm{~m})$ and varied in sizes, the experiment would get a score of 1 . Otherwise, relatively small $(0-0.10 \mathrm{~m})$ and uniform sizes corresponded to a score of 3 .

The duration of the produced gases and dust in the air was divided into three levels. If these products in the air cleared within $15 \mathrm{~s}$, the test case would get a score of 3 . If this duration exceeded one minute, the test case would score 1.

Each experiment was scored by a few people individually according to the criteria above. The scores of the experimental results are listed in Table 2.

The results of the pressured water coupling blasting test were derived from the experimental data by means of orthogonal analysis, as shown in Table 3.
The data in Table 4 indicated that $\mathrm{B} 2 \mathrm{C} 2 \mathrm{~A} 2$ was determined as the optimal combination of factor levels. The indices were very sensitive to the changes in the level of $B$, implying that the pressured water had a significant influence on the effectiveness of blasting. Therefore, the explosive energy could be evenly transferred by the surrounding water which was conducive to the fragmentation of the block, and the results are expected to provide an experimental basis for the optimization and selection of blasting control parameters.

\section{Engineering Practice Analysis}

Blast holes were arranged in the technical roadway of the working face. The ZLJ-650 explosion-proof drilling machine with a $60 \mathrm{~mm}$ alloy bit was used, and the drill diameter was $63 \mathrm{~mm}$. The construction precision was ensured using compass, tilt gauge, and measuring tape. Three groups of blast holes were laid, with a step distance of $7 \mathrm{~m}$ between the groups. The average distance from the holes to the roadway floor was $1.4 \mathrm{~m}$. The construction of blast holes was always ahead of the working face by $60 \mathrm{~m}$, and the blasting operation was ahead of the working face by $40 \mathrm{~m}$. To avoid massive 


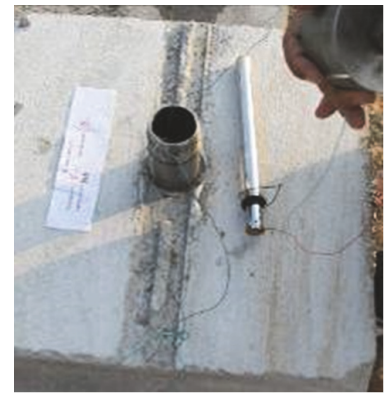

(a)

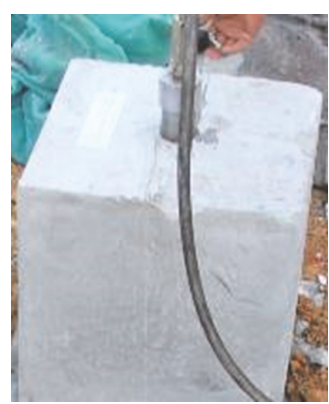

(b)

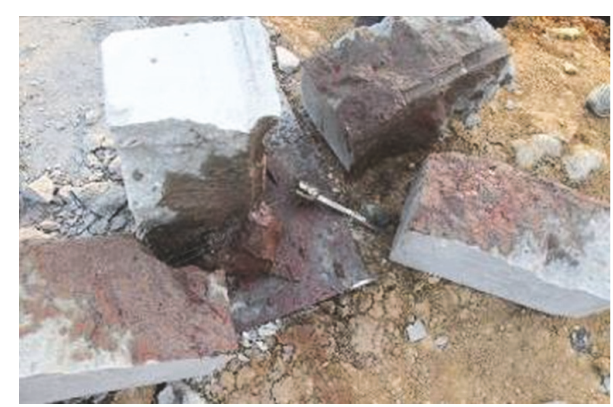

(c)

FIGURE 11: The results of the pressured water coupling blasting in the A2B2C1 case: (a) before being blasted; (b) tube connection; (c) after being blasted.

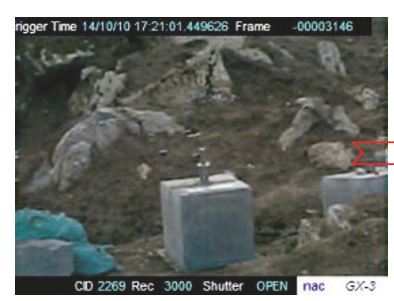

(a)

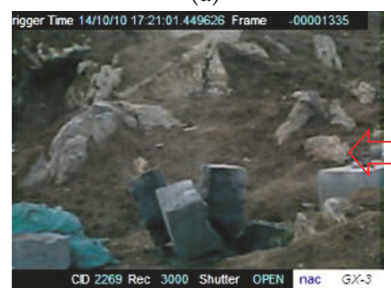

(h)

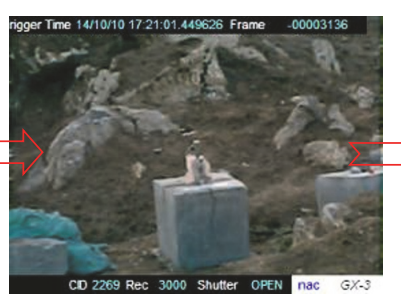

(b)

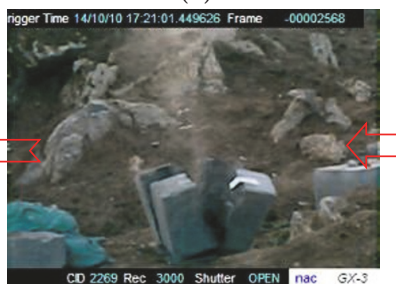

(g)

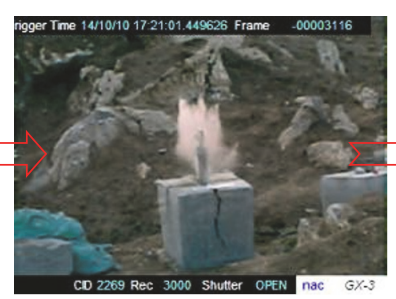

(c)

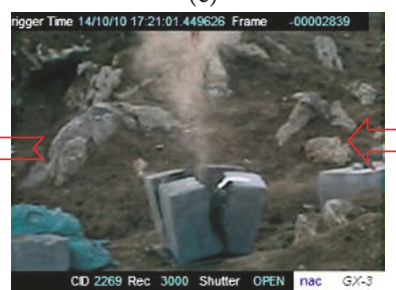

(f)

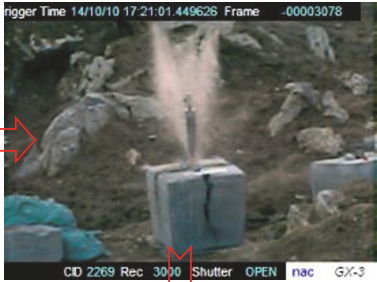

(d)

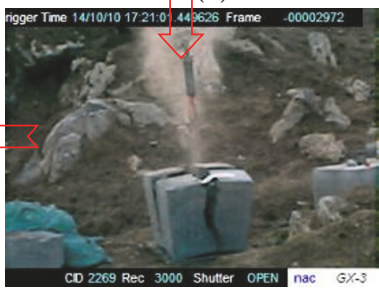

(e)

Figure 12: The pressured water coupling blasting process in the A2B2C1 case: (a) No. 3146; (b) No. 3136; (c) No. 3116; (d) No. 3078; (e) No. 2972; (f) No. 2839; (g) No. 2568; and (h) No. 1335 frame.

filtration loss of the pore-fissure waters, detonation with pressure and water injection was performed. The pressure bearing of the borehole water was maintained at 2.0 MPa. The pipelines for water injection were made of copper, and plastic hoses were used to exhaust the air. The inner and outer diameters of the pipelines were $4 \mathrm{~mm}$ and $6 \mathrm{~mm}$, respectively. The plane layout of the blasting operation and connections between the pipelines are shown in Figure 14.

Special blasting technical roadway was arranged in the roof coal in the middle of the working face. As the working face advanced, cyclic step-distance blasting and roof caving were performed. Parameters of traditional blasting and pressured water coupling blasting were compared by experiment, as shown in Tables 4 and 5, respectively.

Using liquid water as the detonation transmission medium can improve the efficiency of explosive energy higher. This means that the number of explosives required is reduced, facilitating the loading of explosives to a deep borehole. As shown in Table 5, under the same blast hole arrangement, the charge quantity with the pressured water coupling blasting was only $70 \%$ of that in traditional blasting. Moreover, the charging length was $16 \mathrm{~m}$ and the sealing length was the same between the two blasting techniques. The residual space of $7 \mathrm{~m}$ in the blast holes was filled by the pressured water.

The damage of coal wall under the two blasting techniques is illustrated in Figure 15.

In traditional blasting, the coal wall was only damaged to a limited degree even though the full length of the blast hole was filled with explosives. The equivalent length of the broken-out section was about $0.7 \mathrm{~m}$, and the depth of damage was about $0.3 \mathrm{~m}$. The size of the thrown-off funnel on the surface of the blasted coal body was small. On the contrary, pressured water coupling blasting in hard coal rocks showed a significant increase in the utilization efficiency of energy generated by blasting. The coal wall was seriously damaged. The equivalent length of damage was about $7.0 \mathrm{~m}$, and the depth of damage was about $6.5 \mathrm{~m}$. Seven anchor bolts were pulled out, and the size of the thrown-off funnel was larger. The thrown-off coal took up nearly $1 / 3$ of the area of the roadway cross-section. The above results fully demonstrate the high efficiency of pressured water coupling blasting.

Appearance of pressure in the support column in the working face was monitored, and the improvements of stress 


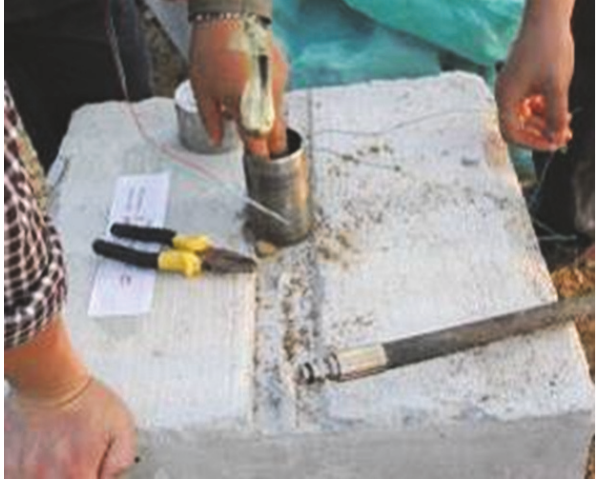

(a)

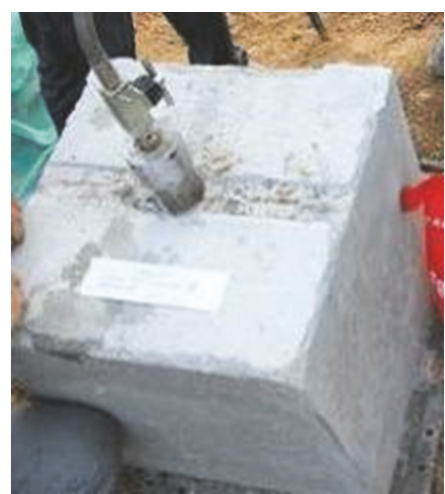

(b)

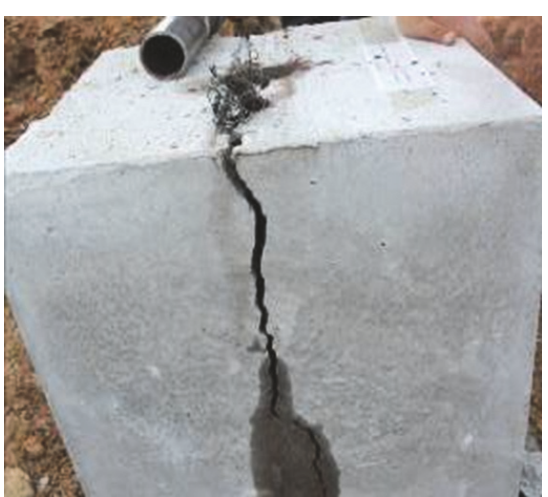

(c)

FIGURE 13: The results of the pressured water coupling blasting in the A1B2C2 case: (a) before being blasted; (b) tube connection; (c) after being blasted.

TABLE 2: Scores of the experimental results.

\begin{tabular}{|c|c|c|c|c|c|c|c|}
\hline $\begin{array}{l}\text { Experimental } \\
\text { combination }\end{array}$ & $\begin{array}{c}\text { Intensity of } \\
\text { sound }\end{array}$ & $\begin{array}{l}\text { Intensity of } \\
\text { flame }\end{array}$ & Dust output & $\begin{array}{l}\text { Scores } \\
\text { Sizes of } \\
\text { fragments }\end{array}$ & Duration of dust & Total score & Average score \\
\hline \multirow{3}{*}{$\mathrm{A} 1 \mathrm{~B} 1 \mathrm{C1}$} & 3 & 2 & 2 & 2 & 1 & 10 & \multirow{3}{*}{11.0} \\
\hline & 2 & 1 & 3 & 3 & 2 & 11 & \\
\hline & 3 & 2 & 4 & 2 & 1 & 12 & \\
\hline \multirow{3}{*}{$\mathrm{A} 2 \mathrm{~B} 1 \mathrm{C} 2$} & 4 & 2 & 4 & 1 & 2 & 13 & \multirow{3}{*}{14.3} \\
\hline & 5 & 2 & 3 & 2 & 3 & 15 & \\
\hline & 4 & 1 & 5 & 2 & 3 & 15 & \\
\hline \multirow{3}{*}{$\mathrm{A} 2 \mathrm{~B} 2 \mathrm{C} 1$} & 5 & 2 & 5 & 1 & 3 & 16 & \multirow{3}{*}{15.7} \\
\hline & 5 & 2 & 4 & 2 & 2 & 15 & \\
\hline & 4 & 2 & 5 & 2 & 3 & 16 & \\
\hline \multirow{3}{*}{$\mathrm{A} 1 \mathrm{~B} 2 \mathrm{C} 2$} & 5 & 2 & 5 & 1 & 3 & 16 & \multirow{3}{*}{16.3} \\
\hline & 5 & 2 & 5 & 2 & 3 & 17 & \\
\hline & 5 & 2 & 5 & 1 & 3 & 16 & \\
\hline
\end{tabular}

TABLE 3: Results of the pressured water coupling blasting test.

\begin{tabular}{lcccc}
\hline \multirow{2}{*}{ Experiment number } & \multicolumn{4}{c}{ Factor } \\
& A & B & C & Average score \\
\hline 1 & 1 & 1 & 1 & 11.0 \\
2 & 1 & 2 & 2 & 16.3 \\
3 & 2 & 1 & 2 & 14.3 \\
4 & 2 & 2 & 1 & 15.7 \\
& 27.3 & 25.3 & 26.7 & \\
\multirow{2}{*}{ Range } & 30.0 & 32.0 & 30.6 & \\
\hline
\end{tabular}

concentration in supports by the two presplitting blasting techniques were compared, as shown in Figure 16.

As seen from Figure 16, the stress on the support column in the working face decreased obviously in the pressured water coupling blasting, compared with traditional blasting. Table 6 shows the distribution of support resistance in the working face.
The measured mean value of terminal resistance of support in the working face was $6495.4 \mathrm{kN}$, accounting for $86.6 \%$ of the rated working resistance. The maximum mean working resistance upon weighting was $7111.6 \mathrm{kN}$, accounting for $94.8 \%$ of the rated working resistance. This allows for sufficient safety margin for support and ensures safe production of the coal mine.

The mean time-weighted resistance of support in the working face was $6749.9 \mathrm{kN}$, accounting for $90.9 \%$ of the rated resistance. The maximum mean was $7069.8 \mathrm{kN}$, accounting for $94.3 \%$ of the rated resistance. Apparently, pressured water coupling blasting for hard coal rocks greatly reduces the mining pressure in the working face.

\section{Conclusions}

The pressured water coupling blasting technique effectively solves the problem of filtration loss in pore-fissure water in coal rocks. This technique can give full play to the load transmission performance of fissure water and help 

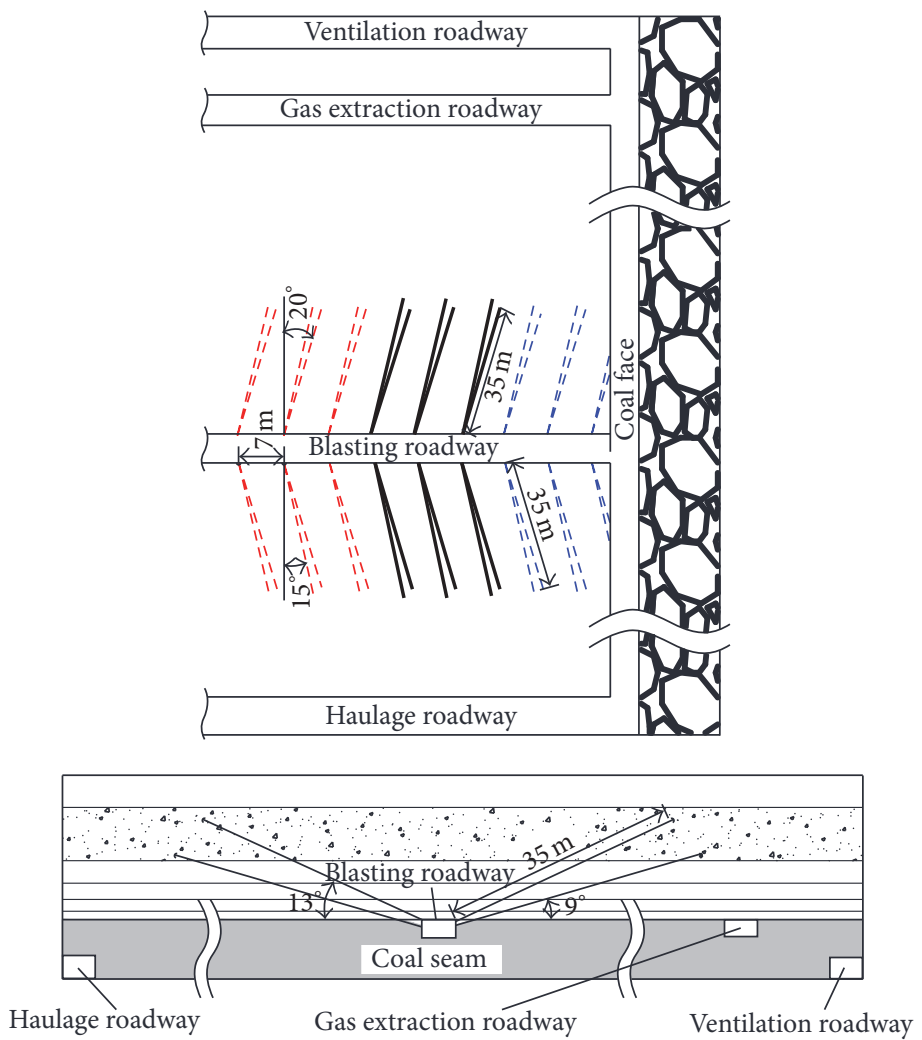

- - - Blasted hole

- Blasting hole

- - Preparation hole

(a) Plane layout of blasting operation

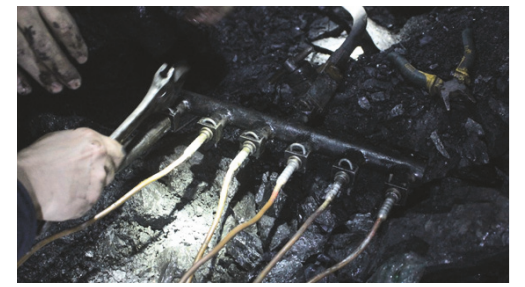

(b) Water throttling device

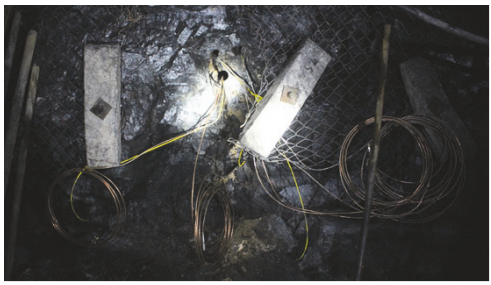

(c) Pipelines connections

FIGURE 14: Plane layout of blasting operation and connections between pipelines.

TABLE 4: Parameters of traditional blasting.

\begin{tabular}{lcccccc}
\hline Level angle $^{\circ}$ & Elevation angle $^{\circ}$ & Altitude $/ \mathrm{m}$ & Hole depth $/ \mathrm{m}$ & Sealing length $/ \mathrm{m}$ & Charging length $/ \mathrm{m}$ & Charge quantity $/ \mathrm{kg}$ \\
\hline 20 & 13 & 7.87 & 35 & 12 & 23 & 46 \\
15 & 13 & 7.87 & 35 & 12 & 23 & 46 \\
15 & 9 & 5.48 & 35 & 12 & 23 & 46 \\
\hline
\end{tabular}

accumulate the energy released by explosion. It proves to be an effective method for controlling high mining pressure in the stope of hard coal rocks. Experiment has demonstrated the high load transmission performance of pore-fissure water in the surrounding rocks. The explosive cartridges display good energy accumulation effect. They are the two main influence factors of pressured water coupling blasting.
The static fragmentation of the entire block resulted from the uniform transmission of the explosive energy by the pressured water. Moreover, the whole blasting process produced no flame, dust, or other hazardous substances, due to the wetting, cooling, and diluting effects of the pressured water. Not only the goal of safe and static rock fragmentation by high-explosive detonation but also a combination of 


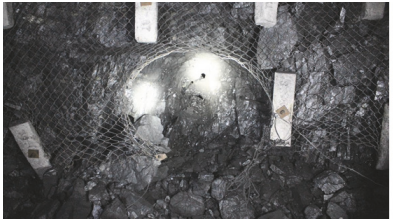

(a) Conditions of traditional blasting
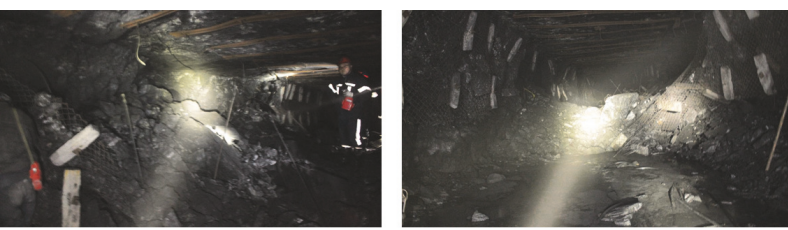

(b) Conditions of pressured water coupling blasting

FIGURE 15: Damage of coal walls under the two blasting conditions.

TABLE 5: Parameters of pressured water coupling blasting.

\begin{tabular}{lcccccc}
\hline Level angle $^{\circ}$ & Elevation angle $^{\circ}$ & Altitude/m & Hole depth/m & Sealing length $/ \mathrm{m}$ & Charging length $/ \mathrm{m}$ & Charge quantity $/ \mathrm{kg}$ \\
\hline 20 & 13 & 7.87 & 35 & 12 & 16 & 32 \\
15 & 13 & 7.87 & 35 & 12 & 16 & 32 \\
15 & 9 & 5.48 & 35 & 12 & 16 & 32 \\
\hline
\end{tabular}

TABLE 6: Distribution of support resistance in the working face.

\begin{tabular}{lcccc}
\hline & Survey line & & Support resistance/kN \\
& & Mean & Mean square error & Maximum \\
\hline \multirow{3}{*}{ Terminal resistance of support } & Head & 5930.7 & 1024.4 & 6791.5 \\
& Middle & 7012.1 & 1125.2 & 7386.6 \\
& Tail & 6543.3 & 1432.5 & 7156.7 \\
& Mean & 6495.4 & 1194.0 & 7111.6 \\
\hline \multirow{2}{*}{ Time-weighted resistance } & Head & 6456.3 & 1391.4 & 6978.3 \\
& Middle & 6958.4 & 1082.0 & 7220.0 \\
& Tail & 6835.1 & 1380.4 & 7011.0 \\
& Mean & 6749.9 & 1284.6 & 7069.8 \\
\hline
\end{tabular}

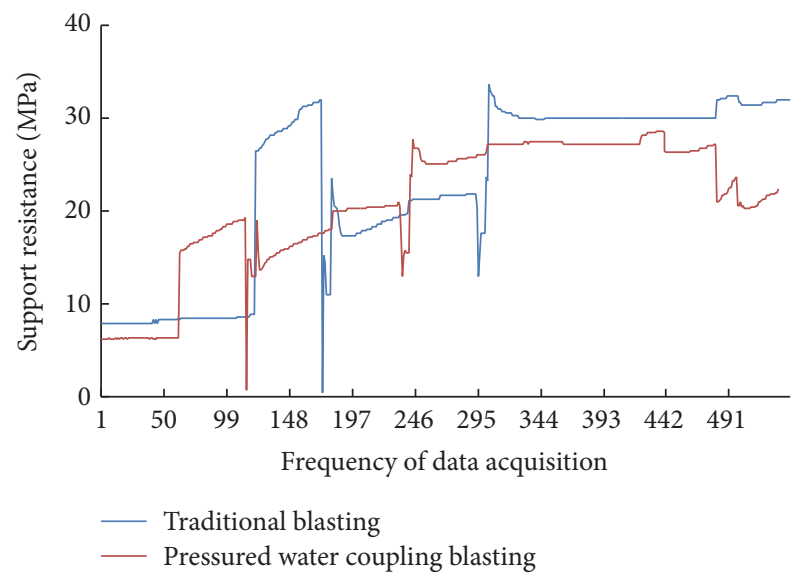

FIGURE 16: Stress acting on supports in the two blasting techniques.

superdynamic blast loading and static loading effect of the pressured water was achieved.

Later we carried out a field experiment on presplitting blasting of hard coal rocks in Datong coal mine. The blasting effects were compared under two different blasting conditions. The results show that a small amount of explosives is sufficient to achieve a satisfactory damage of the coal rocks using pressured water coupling blasting. Moreover, the modified blasting technique reduces the mining pressure and achieves a good blasting control of the hard coal rocks.

\section{Conflicts of Interest}

The authors declare that there are no conflicts of interest regarding the publication of this paper.

\section{Acknowledgments}

The study has been supported by the National Natural Science Foundation (nos. 51604262 and 51574220) and by the Foundation Research Project of Jiangsu Province (no. BK20160256).

\section{References}

[1] J. X. Yang, Study on Confined Blasting Control Mechanism of Hard Coal Rock with High Safety and Efficiency and Test Analysis, China University of Minning \& Technology, Xuzhou, China, 2015.

[2] B. Yu, Study on Strong Pressure Behavior Mechanism and Roof Control of Fully Mechanized Top Coal Caving in Extra Thickness Seam in Datong Coal Mine, China University of Minning \& Technology, Xuzhou, China, 2014. 
[3] B. Yu, C.-Y. Liu, J.-X. Yang, and J.-R. Liu, "Mechanism of strong pressure reveal under the influence of mining dual system of coal pillar in Datong mining area," Journal of the China Coal Society, vol. 39, no. 1, pp. 40-46, 2014.

[4] A. Ramezanzadeh and M. Hood, "A state-of-the-art review of mechanical rock excavation technologies," International Journal of Mining \& Environmental Issues, vol. 1, no. 1, pp. 29-39, 2010.

[5] W. Y. Wu and J. X. Li, "Experimental study and application on control blasting with water coupled charge in tunneling," Nonferrous Metal, no. 5, pp. 20-21, 2003.

[6] F. Ming, W. H. Zhu, and Q. D. Li, "Application of watercouple charge blasting in tunnel excavation," Chinese Journal of Underground Space and Engineering, vol. 8, no. 5, pp. 1008-1013, 2012.

[7] W. C. Zhu, C. H. Wei, S. Li, J. Wei, and M. S. Zhang, "Numerical modeling on destress blasting in coal seam for enhancing gas drainage," International Journal of Rock Mechanics and Mining Sciences, vol. 59, pp. 179-190, 2013.

[8] W. Wang, X.-C. Li, L. Shi, and Z.-M. Fang, "Discussion on decoupled charge loosening blasting in deep rock mass," Rock and Soil Mechanics, vol. 29, no. 10, pp. 2837-2842, 2008.

[9] Q. Zong and Q. Luo, "Experimental study on distribution character of blasting stress when boreholes with water couple charge," Journal of Experimental Mechanics, vol. 21, no. 3, pp. 393-398, 2006

[10] Q. Zong, Y. C. Li, and Y. Xu, "Preliminary discussion on shock pressure on hole wall when water couple charge blasting in the hole," Journal of Hydrodynamics, vol. 19, no. 5, pp. 610-615, 2004.

[11] S. L. Yan and Y. Xu, "Numerical simulation of water-coupled charge rock blasting mechanism," Chinese Journal of Underground Space and Engineering, vol. 1, no. 6, pp. 921-924, 2005.

[12] C. E. Anderson Jr, T. Behner, and C. E. Weiss, "Mine blast loading experiments," International Journal of Impact Engineering, vol. 38, no. 8-9, pp. 697-706, 2011.

[13] Z. Y. Jin, C. Y. Yin, Y. Chen, and H. X. Hua, "One-dimensional analytical model for the response of elastic coatings to water blast," Journal of Fluids and Structures, vol. 59, pp. 37-56, 2015.

[14] J. M. Boteler and G. T. Sutherland, "Tensile failure of water due to shock wave interactions," Journal of Applied Physics, vol. 96, no. 11, pp. 6919-6924, 2004.

[15] V. S. Deshpande and N. A. Fleck, "One-dimensional response of sandwich plates to underwater shock loading," Journal of the Mechanics and Physics of Solids, vol. 53, no. 11, pp. 2347-2383, 2005.

[16] J. M. Pereira, J. Campos, and P. B. Lourenço, "Masonry infill walls under blast loading using confined underwater blast wave generators (WBWG)," Engineering Structures, vol. 92, pp. 69-83, 2015.

[17] S. H. Cho, Y. Nakamura, and K. Kaneko, "Dynamic fracture process analysis of rock subjected to stress wave and gas pressurization," International Journal of Rock Mechanics \& Mining Sciences, vol. 41, no. 3, pp. 433-440, 2004.

[18] M. Goodarzi, S. Mohammadi, and A. Jafari, "Numerical analysis of rock fracturing by gas pressure using the extended finite element method," Petroleum Science, vol. 12, no. 2, pp. 304-315, 2015.

[19] F. V. Donzé, J. Bouchez, and S. A. Magnier, "Modeling fractures in rock blasting," International Journal of Rock Mechanics and Mining Sciences, vol. 34, no. 8, pp. 1153-1163, 1997.

[20] V. R. Feldgun, Y. S. Karinski, and D. Z. Yankelevsky, "Experimental simulation of blast loading on structural elements using rarefaction waves-theoretical analysis," International Journal of Impact Engineering, vol. 102, pp. 86-101, 2017.

[21] I. Edri, Z. Savir, V. R. Feldgun, Y. S. Karinski, and D. Z. Yankelevsky, "On blast pressure analysis due to a partially confined explosion: I. experimental studies," International Journal of Protective Structures, vol. 2, no. 1, pp. 1-20, 2011.

[22] J. X. Yang, C. Y. Liu, B. Yu, and F. F. Wu, "The effect of a multigob, pier-type roof structure on coal pillar load-bearing capacity and stress distribution," Bulletin of Engineering Geology and the Environment, vol. 74, no. 4, pp. 1267-1273, 2014.

[23] S. H. Chen and C. M. Lin, "Features of rock fragmented by water blasting," Journal of China Coal Society, vol. 21, no. 1, pp. 24-29, 1996. 


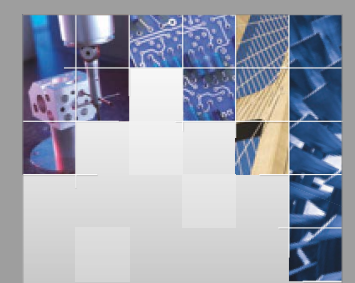

\section{Enfincering}
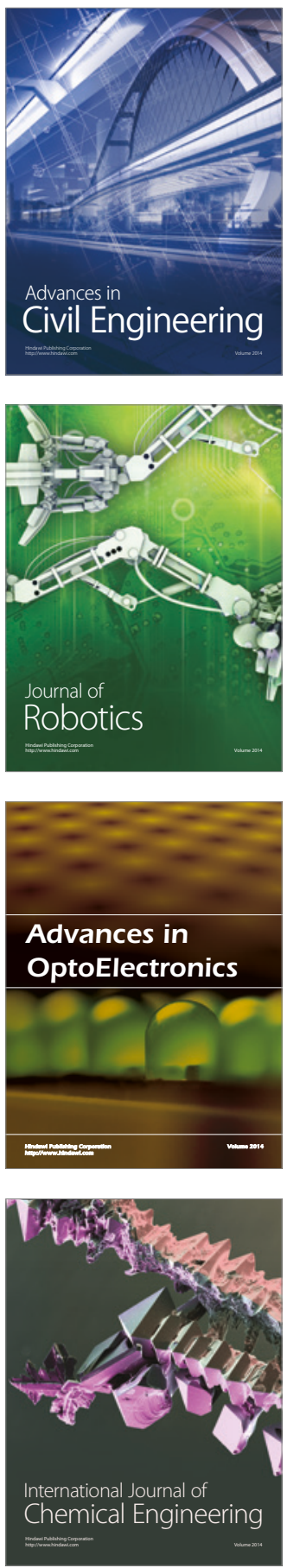

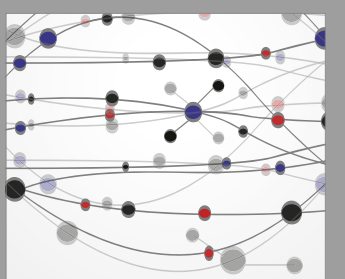

The Scientific World Journal

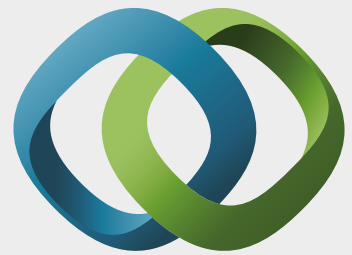

\section{Hindawi}

Submit your manuscripts at

https://www.hindawi.com
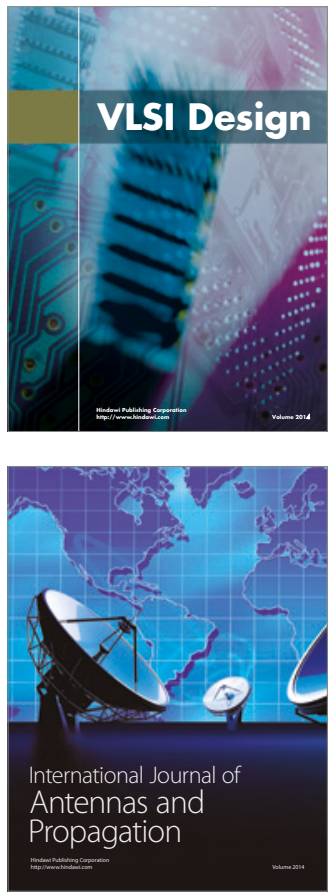

\section{Rotating}

Machinery
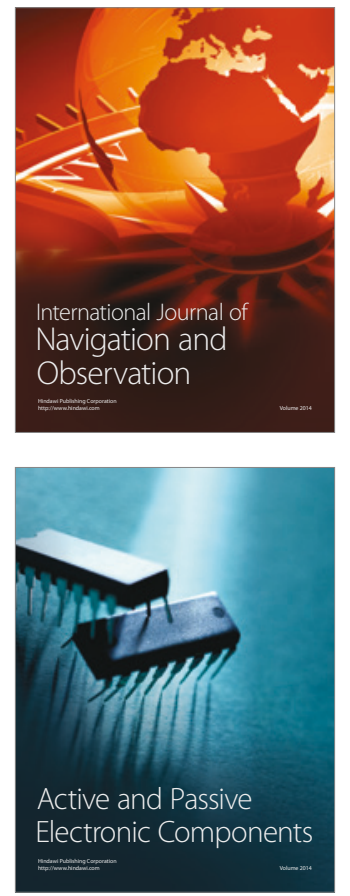
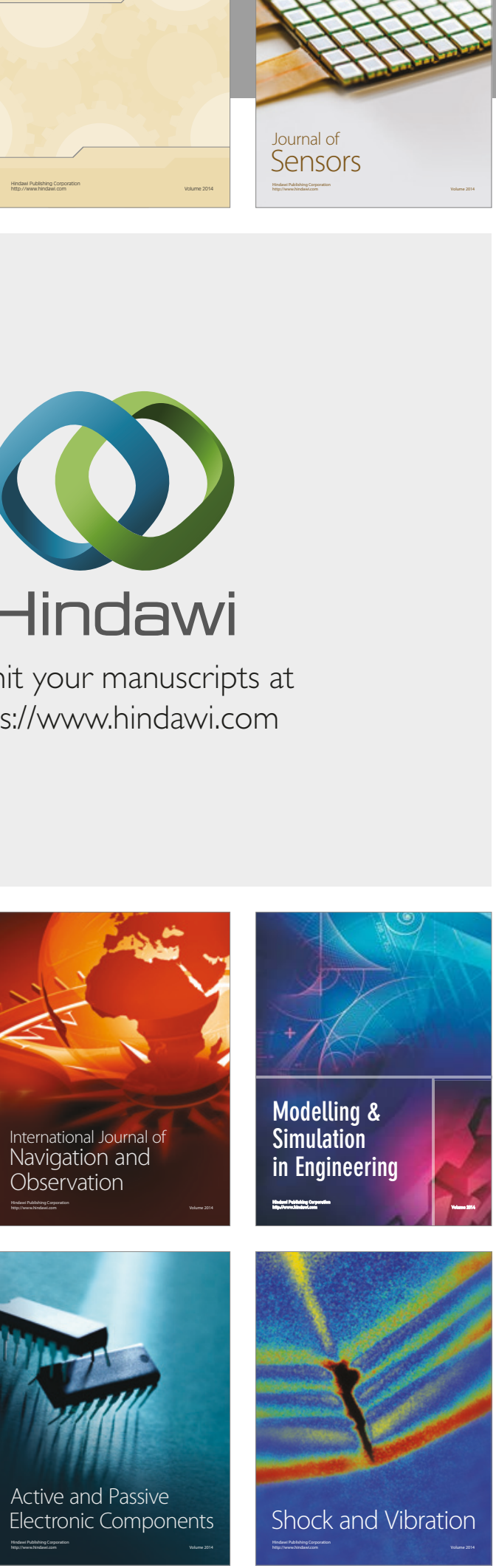
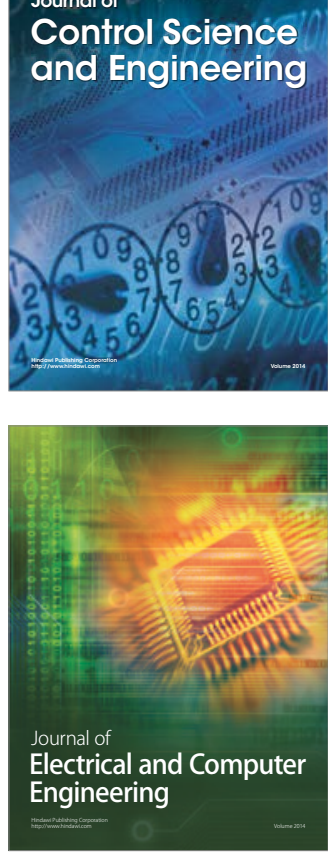

Distributed

Journal of

Control Science

and Engineering
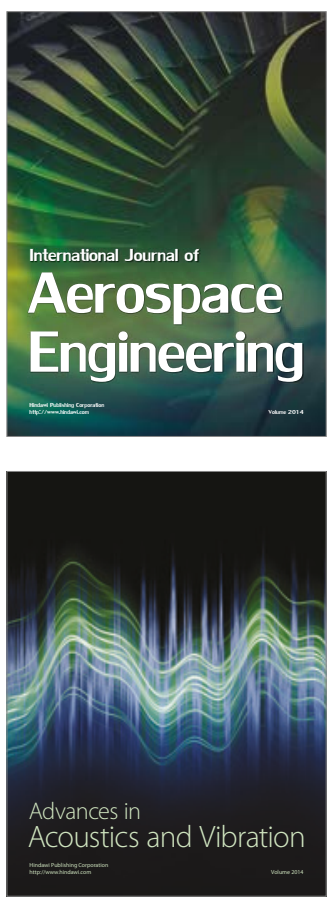

Sensor Networks 